University of Nebraska - Lincoln

DigitalCommons@University of Nebraska - Lincoln

Sociology Department, Faculty Publications

Sociology, Department of

March 2006

\title{
Some Guiding Assumptions and a Theoretical Model for Developing Culturally Specific Preventions with Native American People
}

Les B. Whitbeck

University of Nebraska-Lincoln, Iwhitbeck2@unl.edu

Follow this and additional works at: https://digitalcommons.unl.edu/sociologyfacpub

Part of the Sociology Commons

Whitbeck, Les B., "Some Guiding Assumptions and a Theoretical Model for Developing Culturally Specific Preventions with Native American People" (2006). Sociology Department, Faculty Publications. 27. https://digitalcommons.unl.edu/sociologyfacpub/27

This Article is brought to you for free and open access by the Sociology, Department of at DigitalCommons@University of Nebraska - Lincoln. It has been accepted for inclusion in Sociology Department, Faculty Publications by an authorized administrator of DigitalCommons@University of Nebraska - Lincoln. 
Published in Journal of Community Psychology 34:2 (March 2006), pp. 183-192; doi 10.1002/ jcop.20094 Copyright (c) 2006 Wiley Periodicals, Inc. Used by permission.

http://www3.interscience.wiley.com/journal/32213/home

This research was funded by the National Institute on Drug Abuse (DA13580 and DA15333), Les Whitbeck, Principal Investigator. Correspondence: Department of Sociology, University of

Nebraska-Lincoln, 739 Oldfather Hall, Lincoln, NE 68588-0324; 1whitbeck2@unl.edu

The author acknowledges the generous contributions of John Reid, Oregon Social Learning Center in refining and developing the theoretical model.

\title{
Some Guiding Assumptions and a Theoretical Model for Developing Culturally Specific Preventions with Native American People
}

\author{
Les B. Whitbeck \\ University of Nebraska-Lincoln
}

\begin{abstract}
This essay proposes six basic assumptions to guide the development of prevention research partnerships between Native American communities and non-Native American prevention researchers. It also presents a five-stage theoretical model for the development of culturally specific prevention research. The theoretical model addresses the need for: (a) the cultural translation of key prevention constructs pertaining to risk and protective factors and (b) the development of measures of culturally specific risk and protective factors that will contribute to explained variance over and above that explained by traditional European models. "Cultural translation" refers to the process of adapting key variables to reflect their expression in specific social contexts. "Culturally specific risk and protective factors" refers to risk and protective factors unique to a specific culture, such as the protective effects of traditional spirituality and traditional activities in Native American cultures. The essay concludes with short- and long-term goals for prevention research in Native American communities.
\end{abstract}

More than 25 years ago, Trimble (1977) delineated some fundamental ethical concerns for the "sojourner in the American Indian community" (p. 159). "Sojourner" was the appropriate term for most researchers. They were travelers through Native Americans' land and recorded their findings for outsiders. Most left nothing behind. The sojourner built his or her career or profited from a book and traveled on. In response to this cultural exploitation, an informal code of research ethics for researchers working with Native Amer- 
icans has taken shape over the past three decades. Although its specific origins are unclear, it gained momentum during the early and mid-1970s with the raising political consciousness and sovereignty movements among Native American people. It was part of a grassroots backlash at being the object of study (Deloria, 1969, 1991; Maynard, 1974). At the forefront of the call for ethical research, Deloria (1969) pointed out that non-Native American researchers were preying on Native American communities in the name of science to advance their own careers (p. 104). Given their comparatively small numbers, Native Americans were probably the most studied group in North America (Wax, 1991) and had little or nothing to show for it (Deloria, 1991). Their stories, ceremonies, and healing practices were being taken from them and profited on by others. The notion of researcher as predator gained even more credence when the published work and media coverage was problem-focused and stereotyping, often having serious negative consequences for Native American or Alaska Native communities (Foulks, 1989). Over time, considerable agreement has coalesced regarding what constitutes ethical research with Native Americans (Baldwin, 1999; Beauvais, 1999; Norton \& Manson, 1996; Moran, 1995; Stubben, 1995; Trimble, 1977, 1988; Wax, 1991).

\section{Some Guiding Assumptions for Prevention Research with Native Americans}

These ethical guidelines and our collaboration with Native American communities radically revised our thoughts regarding the nature of community-researcher partnerships. Perhaps more importantly, our research partnerships with Native American people changed the ways we viewed knowledge. We had to relinquish our role as "experts" and learn to accept different ways of knowing. As we systematically analyzed the results of our baseline survey, we were impressed that time after time we empirically verified what the elders had told us. It felt pretentious and humbling to present lengthy statistically based reports telling the elders what they often already knew. For example, our "discoveries" about the resiliency effects of traditional culture only verified what elders had been saying for years. Our findings regarding the influence of anger on early-onset alcohol and drug use validated what we were told in focus groups. Our research contributions were in the form of small increments concerning specific mechanisms about the origins of anger (e.g., discrimination) and the ways that traditional culture worked (e.g., enhanced prosocial behaviors rather than directly reducing alcohol and drug use). The paradigm in which we worked had already been established by a different way of knowing through years of observation and thought by those who intimately knew the cultural ways.

Gradually, a set of six assumptions (Table 1) concerning culturally specific research emerged from our partnerships with Native Americans. We share them with the hope that they will provide some initial guidelines for culturally specific research, and facilitate successful prevention partnerships between researchers and Native American communities. One of the most fundamental of these assumptions for European researchers concerns generalizing across Native cultural groups. We continually receive feedback from grant reviewers and journal editors regarding the generalizability of our findings. Although there are many shared values and beliefs across Native cultures, it is extremely important to the individual cultures to acknowledge that they are unique. Many of them were traditional enemies. Economies were very different, depending on region, and this affected family structure, division of labor, and spiritual practices. The first assumption for a culturally specific prevention approach is that prevention efforts must proceed nation by nation. The process of prevention building may be similar across nations, and even some of the components of 
Table 1. Guiding Assumptions for Prevention Research Partnerships with Native American Communities

1. Prevention efforts must proceed nation by nation.

2. Native American cultures contain all the necessary knowledge to socialize mentally healthy, alcohol- and drug-free children. This knowledge need not be replaced with information and socialization techniques derived from European culture.

3. Cultural ways and knowledge must be viewed as equal to social science prevention knowledge.

4. There exist within Native American cultures developmental risk and protective factors, which operate independently and in interaction with key risk and protective factors known in the majority population. Failure to identify these factors and consider them will mean that prevention efforts will not address important mechanisms affecting the prevention outcome.

5. Ownership must exist for culturally specific prevention programs to be successful.

6. There is a "hunger" among Native American adults and adolescents for their cultural knowledge.

the prevention program may be similar; however, the language, the values, and traditions on which the prevention is based will be very different. This nation by nation approach is labor-intensive, but it acknowledges the unique role of culture and creates active partnerships that increase local ownership, subject response rates, and sustainability.

Native Americans successfully socialized their children for hundreds of years before and after European contact. They have survived one of the longest, most intense, and purposive policies of cultural extermination ever perpetuated on a people. Many believe that recent problems associated with successful child outcomes have been the result of European American attempts at forced acculturation that included removal of generations of children from their parents to boarding schools, forced eradication of traditional language, making their spiritual practices illegal, and forced removal from their lands (see Duran \& Duran, 1995). Although well-intended, prevention programs based on European values and socialization techniques are sometimes perceived as a continuation of this forced acculturation process and they are understandably resisted. This may be particularly true when prevention programs involve family systems and impose values that do not approximate the family systems and values of the Native American culture.

Our second assumption is based on respectfully listening to the cultural histories of nations with which we worked and learning to trust in them. It is important for European researchers to understand that Native American cultures contain all the necessary knowledge to socialize mentally healthy, alcohol-and drug-free children. Family ways and socialization practices need not be replaced with information and socialization techniques derived from the majority culture. Imposing European socialization techniques is akin to the boarding school catastrophe of the late 19th and early 20th centuries. In their struggle to preserve cultural identity, the nations almost have to resist.

This assumption carries with it an implicit third assumption about ways of knowing. If the Native American culture has within it all the knowledge necessary to successfully socialize children to be mentally healthy and alcohol and drug free, then cultural ways and knowledge must be viewed as equal to social science prevention knowledge. A successful prevention model must avoid the underlying European American bias that scientific knowledge is superior to cultural ways of knowing. Rather, a successful partnership weds the two ways of knowing. Cultural ways support the prevention; scientific knowledge contributes information about key constructs of risk and resiliency and provides ways to 
evaluate prevention outcomes. Respect of cultural ways and cultural experts are crucial to the development of research partnerships. Often, elders in Native American cultures "know" that something works. This knowledge is based on generations of experience, yet it has never been subject to scientific evaluation. Scientific evaluation is a European problem that involves translating what is culturally accepted into another epistemological framework so that those who fund research and other prevention scientists will accept it and support needed interventions. The contribution of scientific evaluation to cultural knowledge is that it helps sort out aspects of cultural ways that are most effective and the best ways to present them.

The fourth assumption derives from assumptions two and three. Based on cultural ways of knowing, there exist within Native American cultures developmental risk and protective factors, which operate independently and in interaction with key risk and protective factors known in the majority population. Failure to identify these factors and consider them will mean that prevention efforts will not address important mechanisms affecting the prevention outcome. The most significant cultural risk comes from inherent contradictions between cultural values (Duran \& Duran, 1995; Morrissette, 1994; Yellow Horse Brave Heart, 1999). For example, many Native American nations value sharing, putting the needs of the community before your own, not speaking out in ways that may show disrespect for others, respect for elders, respect for the land, and noncompetitiveness (Brant, 1990; Hornett, 1990). Yet to be successful at school, a Native American child must learn to speak out, be competitive and be individualistic, and to view the land as a resource to be exploited (Dehyle, 1992; Sanders; 1987; Swisher \& Dehyle, 1989; Van Hamme, 1996). Success in European culture may depend on learning to live in contradictory worlds (LaFromboise \& Rowe, 1983).

Another important cultural risk to the well-being of Native Americans is discrimination (Whitbeck, Hoyt, McMorris, Chen, \& Stubben, 2001a; Zimmerman, Ramierex-Valles, Wahienko, Walter, \& Dyer, 1996). According to Kessler, Mickelson, and Williams (1999) discrimination ranks in power with major stressful life events, such as death of a loved one, divorce, and job loss. They suggest that "the conjunction of high prevalence and strong impact would mean that discrimination is among the most important of all the stressful experiences that have been implicated as causes of mental health problems" ( $p$. 224). We have found that the effect of discrimination is a contributing factor to early-onset substance abuse among Native American adolescents mediated by anger and related delinquent behaviors (Whitbeck et al., 2001a).

Native Americans who live on reservations also are subject to more numerous and more serious stressful life events than their European American counterparts. For example, Native American fifth through eighth graders were twice as likely as rural Iowa seventh graders to report having moved in the past year, 3 times more likely to have changed schools, and 25 times more likely to have a family member who was a victim of a crime. Among adults, compared to rural Iowa parents of seventh graders, the Native American mothers and fathers in one of our studies were more than 6 times more likely to have been robbed or burglarized in the past year, twice as likely to have a close friend die, twice as likely to have had a serious illness or injury, 3 times more likely to have experienced job lay-off, 16 times more likely to have started receiving some sort of government assistance, and 4 times more likely to have taken financial responsibility for another family member. Negative life events take their tolls in physical and mental health (Kessler \& Magee, 1993), marital conflict, and parent effectiveness (Conger \& Elder, 1994).

If there are risk factors related to culture, there are also important protective factors associated with cultural traditions. Traditional practices, traditional spirituality, and cul- 


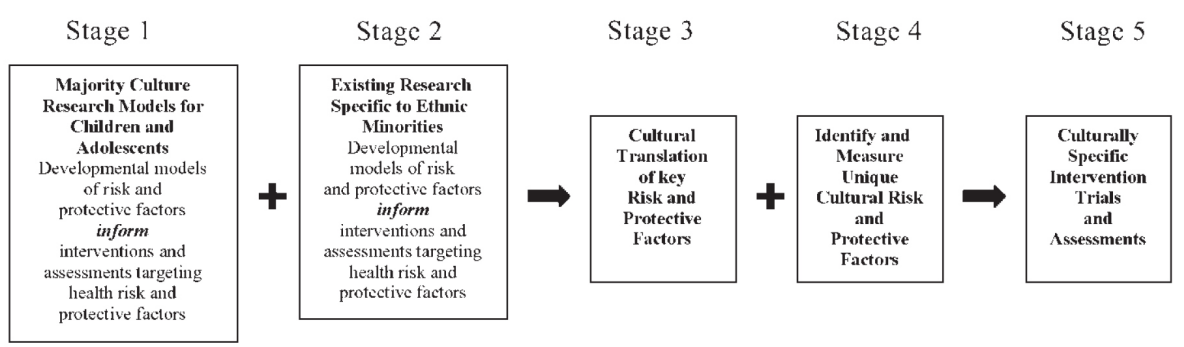

Figure 1. Theoretical model for a culturally specific prevention.

tural identity are positively related to prosocial behaviors of children, academic success, and self-efficacy (Whitbeck, Hoyt, Stubben, \& LaFromboise, 2001b; Zimmerman et al., 1996). Engaging in traditional cultural practices buffers symptoms in Native American adults (Whitbeck, McMorris, Hoyt, Stubben, \& LaFromboise, 2002).

Failure to identify and take into account culturally specific risk and protective factors will mean that traditional, majority-based prevention efforts will not address important mechanisms affecting early alcohol and drug use. Moreover, a culturally specific approach is additive in that it culturally translates key prevention concepts of known risk and protective factors in the majority population and then expands the prevention model to include risk and protective factors that exist specifically in the ethnic minority community. Unique cultural effects may be assessed by the extent of their contributions when other key risk and protective factors are considered.

A fifth assumption for culturally specific research is that community ownership must exist for culturally specific prevention programs to be successful. Ownership involves community leadership in identifying the problem that needs to be addressed, creating the intervention, and implementing the intervention. This means that the prevention program must be developed within the culture via knowledge from elders, service providers, tribal leaders, and community advisory boards. Moreover, the intervention must be implemented within the culture by community co-investigators, permanent staff, facilitators, and interviewers. Finally, the product of the prevention effort belongs to the community.

Our prevention work always begins with a community-identified problem and an invitation to create a working alliance via a tribal resolution. From there, our work goes forward in systematic steps. First, we work with various groups (always including input from elders) to further define the problem and provide essential measures that culturally translate key concepts (e.g., adapting parenting measures to fit cultural ways of monitoring children) and to develop culturally unique measures (e.g., measures of spirituality and traditional practices) needed to understand specific cultural influences. Second, we do a baseline survey that identifies the extent of the problem and allows for analyses that identify specific mechanisms associated with it. Third, we design the prevention components in consultation with elders, services providers, youth, and parents. Fourth, we pilot the prevention with the target age group and families and get their feedback. We have elders observe and evaluate the pilot sessions and get their feedback. Only then do we move to a controlled trial.

It is important to note that through this process all of the staff, including focus group facilitators, interviewers, and facilitators for the prevention program pilot, consists of Native American people. The participants never deal directly with a non-Native American. This creates trust on the part of the participants and ownership on the part of tribal members. 
Our sixth and final assumption is based on learning from elders and service providers, from the survey baseline studies, and from controlled prevention trials. There is a "hunger" among Native American adults and adolescents for their cultural knowledge. Of course, this will vary by nation and even among communities within a nation. However, a culturally specific approach seems to tap into receptiveness to cultural traditions. Indeed, there is a sense of urgency among elders and tribal officials to preserve cultural ways before the knowledge keepers are gone. Some nations are losing a pivotal generation of elders; when they are gone, important teachings will be lost. This sense of "hunger" for, and urgent concern about, traditional culture provides an enormous window of opportunity for the development of culturally specific prevention programs in Native American communities. If properly created, these programs at once preserve and teach the cultural traditions and values that strengthen and protect their children.

\section{A Theoretical Model of Culturally Specific Prevention Research}

Native American children and families are embedded in a unique cultural context that poses specific risks and protective factors. Our theoretical model takes into account this cultural context. We propose a five-stage model for developing evidenced-based culturally specific intervention and assessment models with Native Americans. The model begins with the familiarity of key risk and protective factors that European prevention researchers bring to the prevention effort (Stage 1) and their familiarity with previous culturally specific research that has been done with the particular culture (Stage 2). In Stage 3 of the theoretical model, the cultural partnership emerges. Here, the researchers work with cultural experts to adapt or "translate" key risk and protective factors to fit the cultural context. For example, we have found that measures of parenting based on assumptions of the European nuclear family are not effective measures of family influence in Native American extended family structure. Family influence on child outcomes in the cultures with which we work are very complicated, given an array of potential family configurations. Therefore, when we ask the child about adult monitoring, we also ask how many adults (up to five) monitor him or her. (e.g., Who is the person who does this most of the time? Who else?). This captures various family configurations from isolated single mothers to traditional extended families where an uncle, aunt, or grandparent may be a primary source of monitoring and discipline. The construct "monitoring" is the same, but the adaptation allows a more complete picture of how it is carried out within the cultural context. Stage 4 reflects the development of measures or risk and protective factors that may be unique to the culture. For example, we have developed extensive measures of traditional spirituality and traditional practices that are specific to one Native American culture.

Stages 3 and 4 of the model are extremely important in developing prevention programs across cultures. Without Stage 3, the investigators will lose important information by not using culturally valid measures of key constructs. Without Stage 4 , the investigators will be missing important information that will explain more of the variance in risk and protective factors pertaining to the specific culture. Stages 3 and 4 can only be accomplished in cultural partnerships that genuinely respect the knowledge of cultural informants and that work to incorporate this knowledge into the prevention design. Outsiders simply do not have sufficient information to create or evaluate culturally relevant prevention programs. 
In summary, although the proposed theoretical model was developed for work with Native American communities, it applies to culturally specific prevention work in any culture. The significance of the theoretical model is twofold: (a) it takes into account the need to adapt culturally key constructs of risk and resilience to fit the social context and (b) it posits independent effects of culturally specific risk and protective factors that are omitted in traditional developmental models of risk and resiliency.

\section{Short-Term Partnerships, Long-Term Goals}

Native American nations are losing precious knowledge keepers every day. To bridge the gap between the present situation and the time when independent Native American investigators lead such research, and to respond to the urgency of the pending loss of a pivotal generation, we are proposing "short-term" partnerships between European researchers and Native American communities. These partnerships would build on the assumptions of culturally specific research and have two purposes. The first is to begin the development and implementation of culturally specific prevention programs immediately. The second is to train a new generation of Native American prevention researchers who will take over the prevention process and move it forward from within the cultures. The ultimate goal of these short-term partnerships is to create the infrastructure for the development, implementation, and sustainability of prevention programs within specific Native American communities. Our prevention research experience with Native American people is that the more "Native American" the prevention components and the delivery of the prevention components, the more welcomed and more effective the intervention.

Although it will take time, there is an acute need for indigenous prevention researchers who can do the needed work completely from within. Some Native American cultures have powerful stories and ceremonies not meant for outsiders to participate in or even to hear. Some have norms about what time of year certain traditional stories may be told and when certain ceremonies should take place. These valuable resources are going unused as long as the prevention efforts involve outsiders. The reason for the short-term nature of the proposed partnerships is our belief that it is time for Europeans to fade into the background and to let the cultures heal themselves. The long-term goal is to train a new generation of Native American prevention researchers to carry on and refine the process.

If cultures really are to heal from within, it will mean some policy changes for those who fund prevention programs and other prevention scientists. First, there needs to be an aggressive recruitment and training program for Native American prevention researchers. The goal of this training would be to create a generation of Native American prevention researchers who will be able to meld prevention science with tradition. This would also break the European monopoly on funded research pertaining to Native Americans. Second, because of the urgency posed by the loss of the knowledge of another generation of elders, there needs to be immediate outreach to Native American communities that encourages the development of traditionally based prevention programs. These initiatives should seek ways to put Native Americans in charge.

There are several important caveats to implementing this suggestion. The most important is that each reservation has "hangs around the reservation" European consultants of widely varying expertise and commitment who make their livings working with the nations. Funding initiatives should take into account the qualifications of European consul- 
tants and team Native American reservations with known prevention research programs and experienced prevention researchers. Program evaluators are simply not enough to insure quality prevention research. Second, European prevention researchers who wish to work with Native American nations need training. One model might be to bring prevention researchers together with elders and service providers from interested Native American communities and have the Native American cultural experts train the researchers on creating respectful and potentially productive partnerships. This would reduce the current trial-and-error approach and, hopefully, avoid misunderstandings that result in researchers being asked to leave reservations. Third, funding sources could require that any application that involves Native Americans have a coinvestigator from the Native American community and a tribal resolution. This requirement would mean that the European investigator had done his or her "homework" prior to submitting an application that has to do with Native Americans.

A related policy implication is helping put mechanisms into place that will reduce or eliminate research exploitation on Native American reservations. Although this process is already well underway on some reservations, funding sources and agencies that deal with Native American communities should accelerate training and development of reservation Internal Review Boards to evaluate the quality and quantity of social science research conducted on reservations. Nations continually receive proposals and requests for all types of research agendas. Some are ethical and work through tribal governments and some do not. Although some leave something behind, too often, reservation leaders tell us that researchers still do not observe this basic courtesy. Trained tribal Internal Review Boards would provide a centralized evaluation process for proposed research to ensure it is done properly and that it addresses community concerns.

\section{Closing the Circle}

There is a profound sense of urgency in Native American communities surrounding the continuing loss of important knowledge holders. We believe that European researchers and funding sources have an obligation to share this urgency and work with Native American leaders in the proper ways to institute cultural ways of healing and prevention. The processes we have outlined are derived from many sources and only mark a beginning. The immediate goal is to facilitate cultural healing. At some point, if the work is done in the right way, what began as prevention research partnerships will evolve into independent Native American prevention research that can take full advantage of cultural ways to promote the health and well-being of their people.

\section{References}

Baldwin, J. (1999). Conducting drug abuse prevention research in partnership with Native American communities: Meeting challenges through collaborative approaches. Drugs \& Society, 14, 77-92.

Beauvais, F. (1999). Obtaining consent and other ethical issues in the conduct of research in American Indian communities. Drugs \& Society, 14, 167-184.

Brant, C. (1990). Native ethics and rules of behavior. Canadian Journal of Psychiatry, 35, 534-539.

Conger, R. \& Elder, G. (1994). Families in a changing society: Hard times in rural America. New York: Aldine. Dehyle, D. (1992). Constructing failure and maintaining culture identity: Navajo and Ute school leavers. Journal of American Indian Education, 31, 34-47. 
Deloria, V. (1991). Commentary: Research, redskins, and reality. American Indian Quarterly, 15, 457-468.

Deloria, V. (1969). Custer died for your sins. New York: Avon.

Duran, E., \& Duran, B. (1995). Native American postcolonial psychology. Albany, NY: SUNY Press.

Foulks, E. (1989). Misalliances in the Barrow Alcohol Study. American Indian and Alaska Native Mental Health Research, 2, 7-17.

Hornett, D. (1990). Elementary age tasks, cultural identity, and the academic performance of young American Indian children. Action in Teacher Education, 12, 43-49.

Kessler, R., \&. Magee, W. (1993). Childhood adversities and adult depression: Basic patterns of association in a U.S. national survey. Psychological Medicine, 23, 679-690.

Kessler, R., Michelson, K., \& Williams, D. (1999). The prevalence, distribution, and mental health correlates of perceived discrimination in the U.S. Journal of Health and Social Behavior, 4, 208-230.

LaFromboise, T., \& Rowe, W. (1983). Skills training for bicultural competence: An integrative approach. The Counseling Psychologist, 18, 589-595.

Maynard, E. (1974). The growing negative image of the anthropologist among American Indians. Human Organization, 4, 402-404.

Moran, J. (1995). Culturally sensitive alcohol prevention research in ethnic communities. In P. Langton, L. Epstein, \& M. Orlandi, (Eds.), The challenge of participatory Research: Preventing alcohol-related problems in the ethnic community (CSAP Cultural Competence Series 3, pp. 43-56) (DHHS Publication No. (SMA) 95-3042). Washington, DC: U.S. Department of Health and Human Services.

Morrissette, P. (1994). The holocaust of first nation people: Residual effects on parenting and treatment implications. Contemporary Family Therapy, 16, 81-393.

Norton, L., \& Manson, S. (1996). Research in American Indian and Alaska Native communities: Navigating the cultural universe of values and process. Journal of Consulting and Clinical Psychology, 64, 856-860.

Sanders, D. (1987). Cultural conflicts: An important factor in the academic failures of American Indian students. Journal of Multicultural Counseling and Development, 15, 81-89.

Stubben, J. (1995) American Indian alcohol prevention research: A community advocate's perspective. In P. Langton, L. Epstein, \& M. Orlandi, (Eds.), The challenge of participatory research; Preventing alcohol-related problems in the ethnic community (CSAP Cultural Competence Series 3, pp. 259277) (DHHS Publication No. (SMA) 95-3042). Washington, DC: U.S. Department of Health and Human Services.

Swisher, K., \& Deyhle, D. (1989). The styles of learning are different but the teaching is just the same: Some suggestions for teachers of American Indian youth. Journal of American Indian Education, 28, 1-14.

Trimble, J. (1977). The sojourner in the American Indian community: Methodological issues and concerns. Journal of Social Issues, 33, 159-174.

Trimble, J. (1988). Putting the ethic to work: Applying social-psychological principles in cross-cultural settings. In M. Bond (Ed.), The cross-cultural challenge to social psychology (pp. 109-212). Newbury Park, CA: Sage.

Van Hamme, L. (1996). American Indian cultures and the classroom. Journal of American Indian Education, 21-27.

Wax, M. (1991). The ethics of research in American Indian communities. American Indian Quarterly, $15,431-476$.

Whitbeck, L., Hoyt, D., McMorris, B., Chen, X., \& Stubben, J. (2001a). Perceived discrimination and early substance abuse among American Indian children. Journal of Health and Social Behavior, 42, 405-424. 
Whitbeck, L., Hoyt, D., Stubben, J., \& LaFromboise, T. (2001b). Traditional culture and academic success among American Indian children in the upper Midwest. Journal of American Indian Education, 40, 48-60.

Whitbeck, L., McMorris, B., Hoyt, D., Stubben, J., \& LaFromboise, T. (2002). Perceived discrimination, traditional practices, and depressive symptoms among American Indians in the upper Midwest. Journal of Health and Social Behavior, 43, 400-418.

Yellow Horse Brave Heart, M. (1999). Oyate ptayela: Rebuilding the Lakota nation through addressing historical trauma among Lakota parents. Journal of Human Behavior in the Social Environment, 2, 109-126.

Zimmerman, M., Ramierex-Valles, J., Wahienko, K., Walter, B., \& Dyer, S. (1996). Enculturation hypothesis: Exploring direct and protective factors among Native American youth. In H. McCubbin, E. Thompson, A. Thompson, \& J. Fromer (Eds.), Resiliency in ethnic minority families, Vol 1. Native and immigrant American families (pp. 199-219). Madison, WI: University of Wisconsin. 